\title{
Modification of the treatment protocol as a strategy in the control of the cholera epidemic in Haiti 2016-2017
}

\author{
Carlos Montufar Salcedo* \\ Director, Asdrúbal de la Torre Hospital, Ecuador
}

\begin{abstract}
Cholera is a diarrheal disease caused by the ingestion of food or water contaminated with Vibrio cholerae. Cholera remains a global threat. Each year there are between 1.3 and 4 million cases in the world and between 21,000 and 143,000 deaths. Haiti has a population of 11 million habitants, however, it only has 911 doctors. Despite the progress made since 2010, when an earthquake sruck the country causing the death of 300,000 people, it would trigger the longest and most serious cholera epidemics ever remembered. The objective of the research was to analyze the contribution of the modification of the treatment protocol in the control of the epidemic, based on the antibiotic therapy (doxycycline / erythromycin) of all diagnosed patients, regardless of their degree of dehydration, whether mild, moderate or severe. At the end of 2016, when the protocol modification was initiated, 41,421 cases were recorded. During 2017, there were 13,681 cases, which corresponded to a decrease in the incidence of $66.9 \%$.
\end{abstract}

\section{Introduction}

Cholera is an acute diarrheal disease caused by the ingestion of food or water contaminated with the Vibrio cholerae bacillus. Cholera continues to be a global threat to public health and an indicator of inequity and lack of social development. The researchers estimate that every year there are between 1.3 and 4 million cases of cholera in the world, and between 21000 and 143000 deaths due to this cause ${ }^{1}$. Cholera is an acute diarrheal disease that, if left untreated, can cause death in a matter of hours. Most infected cases are asymptomatic or have mild symptoms, and can be treated with oral rehydration solutions. It was considered that severe cases quickly needed intravenous fluids and antibiotics. The supply of drinking water and sanitation are essential to control the transmission of cholera and other waterborne diseases. Oral cholera vaccines are considered an additional means of control, but should not replace the conventional measures mentioned. Wellproven oral cholera vaccines should be used in conjunction with water and sanitation improvements to control cholera outbreaks and prevent disease in high-risk areas².

Haiti has a population of 11 million inhabitants (2016), however it only has 911 doctors, 3,018 nurses, 115 hospitals, and 7,375 beds. Around 125 communal sections do not have any health facility ${ }^{3}$. Despite the progress made since 2010, when in January a strong earthquake struck the country, killing more than 300,000 people and in October, the longest and most severe cholera epidemic was reported (more of 805,000 cases and more than 9,000 dead as of January 2017), Haiti still has one of the lowest Human Development Indices in the world (163 out of 188 countries). The strain of cholerae vibrion that would be the initiator of the epidemic in Haiti was identified as serogroup O1, serotype Ogawa ${ }^{4}$.

${ }^{1}$ Ali M, Nelson AR, Lopez AL, Sack D. (2015). PLoS Negl Trop Dis 9: e0003832. doi:10.1371/journal.pntd.0003832.

${ }^{2}$ http://www.who.int/mediacentre/factsheets/fs107/es

${ }^{3} \mathrm{http} / /$ hoy.com.do/deficiente-sistema-sanitario-de-haiti-empuja-pacientes-hacia-rd/ ${ }^{4} \mathrm{http}$ ///www.infectioncontroltoday.com/epidemiology-surveillance/cdc-announceslaboratory-test-results-cholera-outbreak-strain-haiti
In this context and despite the efforts made by the Ministry of Public Health and Population since the beginning of the cholera epidemic, in 2011 there would be 352,033 suspected cases with a case-fatality rate of $0.8 \%$; moreover, the presence of the disease would remain dormant, and in 2015 , five years later, there would still be 30,045 cases with similar lethality.

With a chronic evolution, the epidemic was maintained with an important prevalence, which was losing the ability to attract financing from external cooperation to combat it. This situation created environments of defeatism among health actors, both local and international. With ECHO funding, the Doctors of the World Consortium assumes support for the local Ministry of Health, accompanying $70 \%$ of the national territory with the cholera treatment centers. This important experience of cooperation allowed us to carry out an action research work, in order to control the epidemic, in a context of scarce financial resources.

During 2016, the period in which the intervention was initiated ${ }^{5}$, 41,421 suspected cases were counted, with a lethality of $1 \%$. During this period, anti-cholera vaccination was carried out in the regions with the highest incidence in the country, a factor that also contributed to the control of the epidemic. However, during 2017, the decrease in incidence was global in the country.

Finally, in 2017 , the incidence decreased ${ }^{6}$ by $66.9 \%$ in relation to the previous year, despite a lethality of $1.1 \%$.

${ }^{5}$ The modification of the protocol began in the month of December 2016. ${ }^{6} 13.681$ cases reported.

${ }^{*}$ Correspondence to: Carlos Montufar Salcedo, Director, Asdrúbal de la Torre Hospital, Ecuador, E-mail: carmont53@yahoo.es

Key words: cholera, protocol of treatment, epidemic control

Received: September 14, 2018; Accepted: September 20, 2018; Published: September 25, 2018 
The objective of the present investigation is to analyze the possible contribution of the modification of the cholera treatment protocol ${ }^{7}$ in the current control of the epidemic, that is, the control of contagion based on the antibiotic preventive treatment ${ }^{8}$ of all contact with the confirmed patient, without to import the degree of dehydration, whether mild, moderate or severe, or if hospitalization is required or not, as an element of strategic synergy, together with other sanitary measures adopted in the context.

The importance in identifying effective complementary, low-cost and complex measures in the control of the cholera epidemic in Haiti can greatly contribute to public health experience in similar contexts. The pertinence of the reflective and careful study of the strategies, regulations and protocols of health institutions can provide healthy results in health interventions, subjecting them to the contextual and historical view of each cultural and geographic space where the epidemics develop. The case of the control of the cholera epidemic in Haiti ${ }^{9}$ is therefore an interesting example of analysis and global learning.

\section{Results}

The study presents the total number of cases reported and treated globally in the country by the MSPP before (2016) and after (2017) of applying the variant in the national protocol for the treatment of the disease. The data is presented as a contextualizing element from the beginning reported in 2011 to the present 2018, where the lasting effects of protocol change are perceived (Table 1$)^{10}$.

Source: MINISTERE SANTE PUBLIQUE ET DE LA POPULATION (MSPP). Direction d'Epidémiologie de Laboratoire et de Recherches (DELR). Semaine épidémiologique 15 - 2018.

\section{Discussion}

Cholera care protocols have argued that antimicrobials have a very secondary role in the treatment of cholera and are only indicated for severe cases with severe dehydration ${ }^{11}$. They recognize that they help reduce the volume of stools, shortening the period of symptoms and bacterial excretion. Even the WHO states that antibiotics should be considered in people with cholera with moderate to severe dehydration, exclusively ${ }^{12}$.

However, several authors argue that with effective antibiotic therapy, the elimination rate is reduced by approximately $50 \%$, the disease is shortened by approximately another $50 \%$ and the duration of excretion of Vibrio cholerae in the stool is shortened to 1 or 2 days. Without effective antibiotic therapy, patients continue to excrete V. cholerae for 5 or more days, therefore, patients recover more quickly and require less rehydration fluid [1].

Even from the economic point of view, antibiotic therapy is timely. For example, the outbreak of cholera registered in Peru in 1991 cost the country US $\$ 770$ million, due to the embargoes imposed on the food trade and the damages suffered by tourism ${ }^{13}$.

\section{${ }^{7}$ https://www.cdc.gov/cholera/pdf/haiticholera_trainingmanual_fr.pdf}

${ }^{8}$ Doxiciclyne, Tetraciclyne, Eritromicyne o Azitromicyne in relation with nacional protocol.

${ }^{9} \mathrm{https} / / / \mathrm{www}$. diariolibre.com/mundo/latinoamerica/en-2018-es-posible-que-se-elimine-elcolera-en-haiti-LC 9015148

${ }^{10}$ February 2018 up dated.

${ }^{11}$ Protocolo de atención de pacientes con cólera. Subsecretaría de Salud Pública División de Prevención y Control de Enfermedades Departamento Enfermedades Transmisibles. Chile 2010.

${ }^{12} \mathrm{http}: / /$ www.paho.org/hq/index.php?option=com_docman\&task $=$ doc_view\&Itemid $=270$ \&gid=10815\&lang=es

${ }^{13} \mathrm{http} / /$ www.who.int/topics/cholera/impact/es/
In certain regions of the world, where cholera reproduces on a regular basis, the name of healthy carriers is considerably more important than the detected patients, between 40 and $80 \%$ of the infected individuals, being the transmission function, still little known [2]. Hence the importance of using the use of antibiotics in all patients diagnosed with cholera, regardless of their level of dehydration or severity. Other studies have shown that the risk of contamination increases within a radius of 200 meters around the infected patient during the five days after the clinical presentation of the disease. The risk of infection was much higher for people who lived nearby and decreased as they moved away from the environment [3].

The treatment protocol of the Ministry of Health and Population of Haiti also argued that treatment in the (CTC), cholera treatment centers, should be done with Doxycycline $300 \mathrm{mg}$ single dose in adults and Erythromycin $400 \mathrm{mg}$ TID for three days in pregnant women. In children Erythromycin in suspension or tablets at a dose of $12.5 \mathrm{mg} /$ $\mathrm{kg}$ dose, four times a day for three days. However, this treatment was maintained, exclusively in cases of severe and moderate dehydration.

From the month of December 2016, at the suggestion of the consortium of INGOs Doctors of the World, the National Program for the Fight against Cholera in Haiti (MSPP), made the decision to apply the protocol modification, including antibiotic treatment to all patients diagnosed clinically cholera, including mild dehydration, which represented the largest number of affected.

During 2016 there would be 41,421 cases of cholera in the whole country, according to the Report of the National Network for Cholera Surveillance (RNVC), the following year 2017 the RNVC reported only 13,681 cases. The incidence would decrease by $66.9 \%$ in relation to the previous period. Such an obvious impact on the control of the epidemic had many factors that were enunciated as elements that contributed to the result. One of them was the vaccination carried out by the government of Haiti. 790,000 people were vaccinated in the campaign carried out in $90 \%$ of the adult population of the departments of Grand Anse and South ${ }^{14}$ during the month of November 2016. This activity generated enormous expectations [4]. A positive association was demonstrated between the vaccine and effective protection against the disease, this allowed the WHO to recommend its use [5,6]. However, the efficacy of the vaccine is subject to innumerable doubts because only a single dose was applied, which produces only $40 \%$ protection in a period of six months ${ }^{15}$. Another preponderant factor is that vaccination was carried out only in two departments of a total of ten in the country, and in turn, the modification of the protocol had a national application, corroborating the decline in incidence rates at the national level, from 3,7 to 1.1 per thousand inhabitants, in the vaccinated and unvaccinated zones alike.

The rapid response of the water and sanitation teams to each outbreak of cholera detected in the country was also an important element of support and synergy in the control of the epidemic, although it was a response strategy that was maintained for several years, before the control of the epidemic. One of the most effective contributions was the identification of the temporal space dynamics associated with the risks of dispersion of the epidemic in the Department of Artibonite [7].

\footnotetext{
${ }^{14} \mathrm{http}: / /$ www.who.int/features/2016/haiti-cholera-vaccination/en/

${ }^{15} \mathrm{https}: / / \mathrm{rtvc}$.radiotelevisioncaraibes.com/national/d\%C3\%A 9 bat-la-lutte-contre-lechol\%C3\%A9ra.html?print

http://www.lapresse.ca/international/amerique-latine/201701/06/01-5057089-la-presse-enhaiti-le-vaccin-de-la-controverse.php
} 
Table 1. Summary of the situation of the cholera epidemic in Haiti 2011 to February 2018

\begin{tabular}{|c|c|c|c|c|c|}
\hline Year & Poblation & Cases & Letality institutional & Letality community & Letality Global \\
\hline 2011 & 10248306 & 352033 & 1950 & 977 & 2927 \\
\hline 2012 & 10413211 & 101503 & 597 & 311 & 908 \\
\hline 2013 & 10579230 & 58574 & 403 & 184 & 587 \\
\hline 2014 & 10745665 & 27392 & 209 & 88 & 297 \\
\hline 2015 & 10911819 & 36045 & 224 & 98 & 322 \\
\hline 2016 & 11078033 & 41421 & 307 & 140 & 447 \\
\hline 2017 & 12201437 & 13681 & 110 & 49 & 159 \\
\hline 2018 & 12201437 & 590 & 4 & 0 & 4 \\
\hline
\end{tabular}

Source: MINISTERE SANTE PUBLIQUE ET DE LA POPULATION (MSPP). Direction d'Epidémiologie de Laboratoire et de Recherches (DELR). Semaine épidémiologique 15 - 2018

In similar epidemics, general recommendations have been related to the disinfection and adequate elimination of patient feces, the chlorination of the water pipe system and the realization of sanitary education about boiling and chlorinating drinking water [8]. However, the particular situation of the sanitation system in the country did not facilitate its immediate application. An element that would facilitate the control of the epidemic was the sensitivity of the vibrio to the antibiotic therapy formulated in the protocols (doxycycline and erythromycin), compared with other world experiences, which reported strains with resistance even to ceftriaxone [9].

\section{Conclusions}

The extension of antibiotic therapy to all patients with presumptive diagnosis of cholera, including patients with mild dehydration, propelled the reduction of the period of infection of the disease, because the duration of excretion of Vibrio cholerae in the feces it is shortened to 1 or 2 days.

Without this effective antibiotic therapy, patients continue to excrete $V$. cholerae for 5 or more days, in addition, patients recover more quickly and require less rehydration fluid. Therefore, it is suggested, in similar cases, the global antibiotic therapy, without discrimination of the severity level of the disease or of its level of dehydration. Being an efficient and relevant measure in the context of large cholera epidemics, even more, in the case of health systems with complex fragility.

\section{References}

1. Nelson EJ, Nelson DS, Salam MA, Sack DA (2011) Antibiotics for both moderate and severe cholera. $N$ Engl J Med 364: 5-7. [Crossref]

2. Nelson EJ, Harris JB, Morris Jr JG, Calderwood SB, Camilli A (2009). Cholera transmission: the host, pathogen and bacteriophage dynamic. Nat Rev Microbiol 7: 693.

3. Azman AS, Luquero FJ, Salje H, Mbaībardoum NN (2018) Micro-Hotspots of Risk in Urban Cholera Epidemics. J Infect Dis 218: 1164-1168. [Crossref]

4. Kupferschmidt K (2018) Use of cholera vaccines expands, raising hopes. Science 359: 620-621. [Crossref]

5. Ivers LC (2017) Eliminating Cholera Transmission in Haiti. $N$ Engl J Med 376: $101-$ 103. [Crossref]

6. Schwerdtle P, Onekon CK, Recoche K (2018) A quantitative systematic review and meta-analysis of the effectiveness of oral cholera vaccine as a reactive measure in cholera outbreaks. Prehosp Disaster Med pp: 1-5.

7. Piarroux R, Barrais R, Faucher B, Haus R, Piarroux M, et al. (2011) Understanding the cholera epidemic, Haiti. Emerg Infect Dis 17: 1161-1168. [Crossref]

8. Kwesiga B, Pande G, Ario AR, Tumwesigye NM, Matovu JK, et al. (2018) A prolonged, community-wide cholera outbreak associated with drinking water contaminated by sewage in Kasese District, western Uganda. BMC Public Health 18: 30.

9. Feglo PK, Sewurah M (2018) Characterization of highly virulent multidrug resistan Vibrio cholerae isolated from a large cholera outbreak in Ghana. BMC Res Notes 11: 45.

Copyright: (C2018 Salcedo CM. This is an open-access article distributed under the terms of the Creative Commons Attribution License, which permits unrestricted use, distribution, and reproduction in any medium, provided the original author and source are credited. 